\title{
SKEMA NUMERIK PERSAMAAN LESLIE GOWER DENGAN PEMANENAN
}

\author{
Trija Fayeldi \\ Jurusan Pendidikan Matematika Universitas Kanjuruhan Malang \\ Email: trija_fayeldi@yahoo.com
}

\begin{abstract}
ABSTRAK
Model predator-prey merupakan salah satu model yang sangat banyak diteliti dan dimodifikasi Pada penelitian ini, akan dibangun suatu skema numerik untuk menyelesaikan suatu model predatorprey. Model yang dipilih pada penelitian ini adalah model kontinu Leslie-Gower yang telah dimodifikasi pada pemanenan. Model kontinu tersebut akan didiskritisasi dengan menggunakan metode Euler. Selanjutnya, akan diamati perilaku model hasil diskritisasi tersebut dan pada akhirnya akan diamati apakah perubahan parameter dapat mempengaruhi kestabilan model dengan menggunakan perangkat lunak Matlab. Hasil penelitian menujukkan bahwa perilaku model hasil diskritisasi konsisten dengan model kontinunya. Pada simulasi numerik dengan Matlab, ditunjukkan bahwa perubahan parameter akan mempengaruhi kestabilan model.
\end{abstract}

Kata kunci: predator-prey, Leslie-Gower, stabil, saddle, source, pemanenan.

\section{PENDAHULUAN}

Leslie-Gower memperkenalkan model dengan populasi predator tumbuh mengikuti model logistik [1]. Pada model ini, diasumsikan bahwa bahwa carrying capacity (kapasitas pendukung) predator sebanding dengan banyaknya populasi prey. Model ini kemudian diteliti dan dikembangkan oleh beberapa peneliti. Aguirre mengembangkan penelitian model predator-prey Leslie-Gower dengan penambahan efek [2]. Hasil penelitian ini menunjukkan bahwa model Leslie-Gower dengan penambahan efek Allee dapat memiliki dua limit cycle. Aziz mengkaji model Leslie-Gower dengan mengasumsikan fungsi respon yang menyatakan besarnya pemangsaan predator terhadap prey mengikuti fungsi respon Holling tipe II [3]. Mereka meneliti kestabilan global dan keterbatasan sistem tersebut. Model yang dikembangakan oleh Aziz, dkk. kemudian dimodifikasi dengan penambahan waktu tunda [4]. Dari hasil penelitian, diperoleh bahwa waktu tunda mempengaruhi perilaku dinamik model tersebut. Penelitian ini dikembangkan dengan mengamati bifurkasi dari [5]. Chen memperkenalkan perlindungan terhadap prey dan menunjukkan bahwa perlindungan tidak mempengaruhi perilaku model secara signifikan [6]. Selain itu, pengaruh efek impulsif pada model diteliti oleh Song [7]. Zhu melakukan penelitian model Leslie-Gower dengan fungsi respon Holling tipe II tanpa adanya kontrol impulsif [8] dan mengkaji eksistensi dan kestabilan global solusi periodik positif model dengan mengkonstruksi suatu fungsi Lyapunov..

\section{TINJAUAN PUSTAKA}

\section{Sistem Dinamik Diskrit}

Bentuk umum dari suatu sistem dinamik diskrit dapat dilihat pada Definisi berikut.

\section{Definisi 1}

Misalkan $\vec{x}(n)=\left[x_{1}(n), x_{2}(n), \ldots, x_{k}(n)\right]^{T}$ dan $\vec{G}=$ $\left[g_{1}, g_{2}, \ldots, g_{k}\right]^{T}$.

Bentuk umum dari suatu sistem dinamik diskrit adalah

$$
\vec{x}(n+1)=\vec{G}(\vec{x}(n))
$$

Bentuk (1) disebut sebagai sistem dinamik diskrit nonlinear jika $g_{i}$ memuat perkalian antarvariabel tak bebas, $\forall i=1,2, \ldots, k$.

\section{Definisi 2}

Misalkan $g$ adalah fungsi dari $R$ ke $R$.

Titik $p^{*}$ dikatakan sebagai titik kesetimbangan dari $g$ jika memenuhi $g\left(p^{*}\right)=p^{*}$.

\section{Sistem Dinamik Diskrit Linear}

Bentuk umum persamaan beda orde satu dengan variabel bebas adalah

$$
\vec{x}(n+1)=A \vec{x}(n)
$$

Dengan $A=\left(a_{i j}\right), \forall i=1,2, \ldots, k$ adalah matriks yang bernilai real, dan $\vec{x}(n)=\left[x_{1}(n), x_{2}(n), \ldots\right.$, $\left.x_{k}(n)\right]^{T}, T$ menyatakan transpose dari vektor $A$. Jika diberikan nilai awal $\vec{x}(n)=\vec{x}_{0}$ maka persamaan (2) memiliki solusi umum

$$
\vec{x}(n)=A^{n} \vec{x}(0)
$$

Jika matriks $A$ dapat didiagonalkan maka solusi umum persamaan (2) adalah

$$
\vec{x}(n)=c_{1} \lambda_{1}^{n} \vec{v}_{1}+\ldots+c_{3} \lambda_{k}^{n} \vec{v}_{k}
$$


Dengan $c_{i}$ adalah sembarang konstanta dan $\overrightarrow{v_{l}}$ adalah vektor eigen yang bersesuaian dengan nilai eigen $\lambda_{i}$.

\section{Teorema 1}

Misalkan $F(\lambda)=\lambda^{2}-p \lambda+q$ maka kondisi-kondisi berikut:

1. $F(1)=1-p+q>0$

2. $F(-1)=1+p+q>0$

3. $F(0)=q<1$

merupakan syarat perlu dan cukup agar persamaan tersebut memiliki akar-akar karakteristik $\left|\lambda_{i}\right|, i=1,2$.

\section{Lemma 1}

Jika $F(\lambda)=\lambda^{2}-p \lambda+q$ dengan $\lambda_{1}$ dan $\lambda_{2}$ adalah dua akar dari $F(\lambda)=0$ maka

1. $\left|\lambda_{1}\right|<1$ dan $\left|\lambda_{2}\right|<1$ jika dan hanya jika $F(1)>0, F(-1)>0$, dan $F(0)<1$.

2. $\left|\lambda_{1}\right|<1$ dan $\left|\lambda_{2}\right|>1$ atau $\left|\lambda_{1}\right|>1$ dan $\left|\lambda_{2}\right|$ $<1$ jika dan hanya jika $F(1)>0, F(-1)<$ 0.

3. $\left|\lambda_{1}\right|>1$ dan $\left|\lambda_{2}\right|>1$ jika dan hanya jika $F(1)>0, F(-1)>0$, dan $F(0)>1$.

4. $\lambda_{1}$ dan $\lambda_{2}$ adalah kompleks dan $\left|\lambda_{1}\right|=$ $\left|\lambda_{2}\right|=1$ jika dan hanya jika $F(1)>0, F(1)$ $>0, F(0)=1$, dan $p^{2}-4 q<0$.

\section{Akibat 1}

1. Titik kesetimbangan bersifat stabil asimtotik (sink) $F(1)>0, F(-1)>0$, dan $F(0)$ $<1$,

2. Titik kesetimbangan bersifat tak stabil pelana (saddle) jika $F(1)>0, F(-1)<0$,

3. Titik kesetimbangan bersifat tak stabil (source) jika $F(1)>0, F(-1)>0$, dan $F(0)>$ 1 ,

4. Titik kesetimbangan merupakan titik kesetimbangan non-hyperbolic jika $F(1)>0$, $p^{2}-4 q<0$, dan $q=1$.

\section{Model PredatorPrey Leslie-Gower}

Pada tahun 1948, Leslie dan Gower memperkenalkan model dengan populasi prey tumbuh mengikuti model logistik sehingga pertumbuhan predator juga terbatas disebabkan oleh predator memangsa prey. Selain itu, carrying capacity predator sebanding dengan banyaknya populasi prey, sehingga model Leslie-Gower dinyatakan sebagai sistem persamaan diferensial nonlinear berikut.

$$
\begin{aligned}
& \frac{d x}{d t}=\left(r_{1}-a_{1} y-b_{1} x\right) x \\
& \frac{d y}{d t}=\left(r_{2}-a_{2} \frac{y}{x}\right) y
\end{aligned}
$$

dengan semua parameter bernilai positif. Kedua parameter, yaitu $r_{1}$ dan $r_{2}$ berturut-turut menunjukkan pertumbuhan intrinsik prey dan predator. Parameter $a_{1}$ merupakan parameter interaksi pemangsaan predator terhadap prey. Parameter $b_{1}$ adalah parameter antraksi antar prey, sedangkan $b_{2}$ adalah parameter interaksi antar predator [9].. Model predator prey yang digunakan pada penelitian ini adalah sebagai berikut.

$$
\begin{aligned}
& \frac{d H}{d t}=\left(r_{1}-a_{1} P-b_{1} H\right) H-c_{1} H \\
& \frac{d P}{d t}=\left(r_{2}-a_{2} \frac{P}{H}\right) P-c_{2} P \quad \text { (6b) }
\end{aligned}
$$

Dengan $H$ dan $P$ berturut-turut adalah kepadatan spesies prey dan predator pada waktu $t$. Pada model ini, diasumsikan $0<c_{i}<r_{i}, i=1,2$ untuk mengontrol kepadatan prey dan predator. Model ini mempunyai dua titik kesetimbangan, yaitu $E_{1}$ dan $E_{2}$ berturut turut $E_{1}=\left(\frac{r_{1}-c_{1}}{b_{1}}, 0\right)$ dan titik kesetimbangan $E_{2}=\left(H_{2}, P_{2}\right)$ dengan $H_{2}$ $=\frac{\left(r_{1}-c_{1}\right) a_{2}}{a_{1}\left(r_{2}-a_{2}\right)+a_{2} b_{1}}$ dan $P_{2}=\frac{\left(r_{1}-c_{1}\right)\left(r_{2}-c_{2}\right)}{a_{1}\left(r_{2}-a_{2}\right)+a_{2} b_{1}}$. Menurut Zhu [8], titik kesetimbangan $\left(H^{*}, P^{*}\right)$ bersifat stabil global.

\section{METODOLOGI PENELITIAN}

Metodologi penelitian yang dilakukan pada penelitian ini adalah studi literatur. Pada penelitian ini, persamaan model Leslie-Gower kontinu (6a) dan (6b) didiskritisasi dengan menggunakan metode Euler. Kemudian, dilakukan pencarian titik kesetimbangan dan analisis kestabilan pada titik kesetimbangan tersebut secara lokal. Akhirnya, dilakukan simulasi numerik untuk beberapa kasus parameter model.

\section{HASIL DAN PEMBAHASAN}

\section{Diskritisasi Model}

Pandang kembali (6a) dan (6b). Dengan menggunakan beda maju, persamaan (6a) dan (6b) dapat didiskritisasi menjadi seperti berikut.

$$
\begin{aligned}
& H_{n+1}=H_{n}+\left(k_{1}-a_{1} P_{n}-b_{1} H_{n}\right) H_{n} \\
& P_{n+1}=P_{n}+\left(k_{2}-a_{2} \frac{P_{n}}{H_{n}}\right) P_{n}
\end{aligned}
$$

Dengan $k_{1}=\left(r_{1}-c_{1}\right)$ dan $k_{2}=\left(r_{2}-c_{2}\right)$.

\section{Titik Kesetimbangan Model}

Misalkan titik kesetimbangan dari (7a) dan (7b) adalah $\left(H^{*}, P^{*}\right)$ maka haruslah berlaku $H^{*}=H^{*}+\left(k_{1}-a_{1} P^{*}-b_{1} H^{*}\right) H^{*}$

$P^{*}=P^{*}+\left(k_{2}-a_{2} \frac{P^{*}}{H^{*}}\right) P^{*}$ 
Berdasarkan (8a) dan (8b), diperoleh $H^{*}=0$ atau

$k_{1}-a_{1} P^{*}-b_{1} H^{*}=0$

dan

$P^{*}=0$ atau

$\left(k_{2}-a_{2} \frac{P^{*}}{H^{*}}\right)=0$.

Berdasarkan (8b), jelas $H^{*} \neq 0$.

Substitusikan $P^{*}=0$ ke (9a)

$k_{1}-a_{1}(0)-b_{1} H^{*}=0$

$k_{1}-b_{1} H^{*}=0$

$k_{1}=b_{1} \mathrm{H}^{*}$

$H^{*}=\frac{r_{1}-c_{1}}{b_{1}}$

Sehingga diperoleh $E_{1}=\left(\frac{r_{1}-c_{1}}{b_{1}}, 0\right)$.

Untuk $k_{1}-a_{1} P^{*}-b_{1} H^{*}=0$ diperoleh $P^{*}=\frac{k_{1}-b_{1} H^{*}}{a_{1}}$.

Substitusikan (11) ke (9b), diperoleh

$\left(k_{2}-\frac{a_{2} P^{*}}{H^{*}}\right)=0$

$\left(k_{2}-\frac{a_{2}\left(k_{1}-b_{1} H^{*}\right)}{a_{1} H^{*}}\right)=0$

$\frac{a_{1} k_{2} H^{*}-a_{2}\left(k_{1}-b_{1} H^{*}\right)}{a_{1} H^{*}}=0$

$a_{1} k_{2} H^{*}-a_{2} k_{1}+a_{2} b_{1} H^{*}=0$

$H^{*}\left(a_{1} k_{2}+a_{2} b_{1}\right)=a_{2} k_{1}$

$H^{*}=\frac{a_{2} k_{1}}{a_{1} k_{2}+a_{2} b_{1}}$

Substitusikan (12) ke (11), diperoleh $P^{*}=\frac{k_{1}-b_{1} H^{*}}{a_{1}}$

$P^{*}=\frac{k_{1}-b_{1}\left(\frac{a_{2} k_{1}}{a_{1} k_{2}+a_{2} b_{1}}\right)}{a_{1}}$.

$P^{*}=\frac{k_{1}\left(a_{1} k_{2}+a_{2} b_{1}\right)-a_{2} b_{1} k_{1}}{a_{1}\left(a_{1} k_{2}+a_{2} b_{1}\right)}$

$P^{*}=\frac{k_{1}\left(a_{1} k_{2}+a_{2} b_{1}-a_{2} b_{1}\right)}{a_{1}\left(a_{1} k_{2}+a_{2} b_{1}\right)}$

$P^{*}=\frac{a_{1} k_{1} k_{2}}{a_{1}\left(a_{1} k_{2}+a_{2} b_{1}\right)}$

$P^{*}=\frac{k_{1} k_{2}}{a_{1} k_{2}+a_{2} b_{1}}$.

Sehingga diperleh $E_{2}=\left(\frac{a_{2} k_{1}}{a_{1} k_{2}+a_{2} b_{1}}, \frac{k_{1 k_{2}}}{a_{1} k_{2}+a_{2} b_{1}}\right)$.

\section{Analisis Kestabilan Model}

Analisis kestabilan model dilakukan dengan mengamati perilaku model secara lokal di sekitar titik kesetimbangannya. Misalkan,

$F(H, P)=H+\left(k_{1}-a_{1} P-b_{1} H\right) H$

$G(H, P)=P+\left(k_{2}-a_{2} \frac{P}{H}\right) P$

Matriks Jacobi dari sistem (13a) dan (13b) adalah

$\mathrm{J}=\left(\begin{array}{ll}\frac{\partial F}{\partial H} & \frac{\partial F}{\partial P} \\ \frac{\partial G}{\partial H} & \frac{\partial G}{\partial P}\end{array}\right)$ $=\left(\begin{array}{cc}1+\left(k_{1}-a_{1} P-2 b_{1} H\right) & -a_{1} P \\ \frac{a_{2} P^{2}}{H^{2}} & 1+\left(k_{2}-2 a_{2} \frac{P}{H}\right)\end{array}\right)(14)$

Untuk $E 1$ diperoleh:

$J_{E 1}=\left(\begin{array}{cc}1-k_{1} & -\frac{a_{1} k_{1}}{b_{1}} \\ 0 & 1+k_{2}\end{array}\right)$.

Nilai-nilai eigen dari JE1 adalah $\lambda_{1}=1-k_{1}$ dan $\lambda_{2}$ $=1+k_{2}$. Jelas $\left|\lambda_{2}\right|=\left|1+k_{2}\right|=1+k_{2}>1$.

\section{Lemma}

Jika $0<k_{1}<2$ maka $\left|\lambda_{1}\right|<1$.

\section{Bukti:}

$0<k_{1}<2$

$-2<-k_{1}<0$

$-2+1<-k 1+1<0+1$

$-1<1-k 1<1$

$\left|1-k_{1}\right|<1$

(terbukti)

Berdasarkan lemma tersebut, dapat dituliskan teorema berikut.

\section{Teorema 2}

Jika $k_{1}, k_{2}>0$ maka

1. $E_{1}$ saddle jika $k_{1}<2$

2. $E_{1}$ source jika $k_{1}>2$

3. $E_{1}$ nonhiperbolik jika $k_{1}=2$

Adapun matriks Jacobi untuk $E_{2}$ adalah $J_{E 2}=\left(\begin{array}{cc}1-b_{1} H^{*} & -a_{1} H^{*} \\ \underline{k_{2}^{2}} & 1-k_{2}\end{array}\right)$.

Misalkan, $p$ dan $q$ berturut-turut adalah trace dan determinan $J_{E 2}$ maka dapat ditulis

$p=2-\left(b_{1} H^{*}+k_{2}\right)$

$q=1-\left(b_{1} H^{*}+k_{2}\right)+k_{1} k_{2}$

\section{Lemma 2}

Jika $k_{1}, k_{2}>0$ maka $1-p+q>0$

\section{Bukti:}

Misalkan $k_{1}, k_{2}>0$.

$1-p+q=1-\left[2-\left(b_{1} H^{*}+k_{2}\right)\right]+1-\left(k_{2}+b_{1} H^{*}\right)+k_{1} k_{2}$ $=b_{1} H^{*}+k_{2}+-\left(b_{1} H^{*}+k_{2}\right)+k_{1} k_{2}$ $=k_{1} k_{2}>0$ (terbukti)

\section{Lemma 3}

Jika $H^{*}>\frac{k_{2}}{b_{1}}\left(k_{1}-1\right)$ maka $q<1$.

Bukti:

Misalkan, $H^{*}>\frac{k_{2}}{b_{1}}\left(k_{1}-1\right)$

Maka 


$$
\begin{aligned}
& b_{1} H^{*}>k_{2}\left(k_{1}-1\right) \\
& b_{1} H^{*}>k_{1} k_{2}-k_{2} \\
& b_{1} H^{*}+k_{2}>k_{1} k_{2} \\
& b_{1} H^{*}+k_{2}-k_{1} k_{2}>0 \\
& -\left(b_{1} H^{*}+k_{2}\right)+k_{1} k_{2}<0 \\
& 1-\left(b_{1} H^{*}+k_{2}\right)+k_{1} k_{2}<1 \\
& q<1 \\
& \text { (terbukti) }
\end{aligned}
$$

\section{Lemma 4}

Jika $H^{*}<\frac{1}{2 b_{1}}\left[4+k_{2}\left(k_{1}-2\right)\right]$ maka $1+p+q>0$.

Bukti:

Misalkan $H^{*}<\frac{1}{2 b_{1}}\left[4+k_{2}\left(k_{1}-2\right)\right]$

$H^{*}<\frac{1}{b_{1}}\left[2+\frac{k_{2}}{2}\left(k_{1}-2\right)\right]$

$b_{1} H^{*}+k_{2}<2+\frac{k_{1} k_{2}}{2}$

$2+\frac{k_{1} k_{2}}{2}>b_{1} H^{*}+k_{2}$

$4+k_{1} k_{2}>2\left(k_{2}+b_{1} H^{*}\right)$

$4+k_{1} k_{2}-2\left(b_{1} H^{*}+k_{2}\right)>0$

$1+\left[2-\left(b_{1} H^{*}+k_{2}\right)\right]+\left[1-\left(b_{1} H^{*}+k_{2}\right)+k_{1} k_{2}\right]>0$

$1+p+q>0$ (terbukti).

Berdasarkan Lemma 2, Lemma 3, dan Lemma 4 dapat dibuat Teorema berikut.

\section{Teorema 3}

Jika $\frac{k_{2}}{b_{1}}\left(k_{1}-1\right)<H^{*}<\frac{1}{2 b_{1}}\left[4+k_{2}\left(k_{1}-2\right)\right]$ maka titik kesetimbangan $E_{2}$ akan stabil.

\section{Simulasi Numerik}

Berikut akan disajikan simulasi numerik dari sistem (7a) dan (7b) dengan $c_{1}=0,1 ; r_{1}=0.3 ; c_{2}=$ $0.1 ; r_{2}=0.2 ; a_{1}=0.1 ; b_{1}=0.1 ; a_{2}=0.1$. Pada simulasi tersebut, diperoleh nilai eigen pada titik kesetimbangan $E_{1}=(3,0)$ adalah $\left|\lambda_{1}\right|=0,7$ dan $\left|\lambda_{2}\right|=1,1$ yang berarti titik kesetimbangan $E_{1}$ saddle. Adapun nilai eigen yang diperoleh pada titik kesetimbangan $E_{2}=(1.5,1.5)$ adalah $\left|\lambda_{1}\right|=$ 0,8832 dan $\left|\lambda_{2}\right|=0,8832$ yang berarti titik kesetimbangan $E_{2}$ stabil.

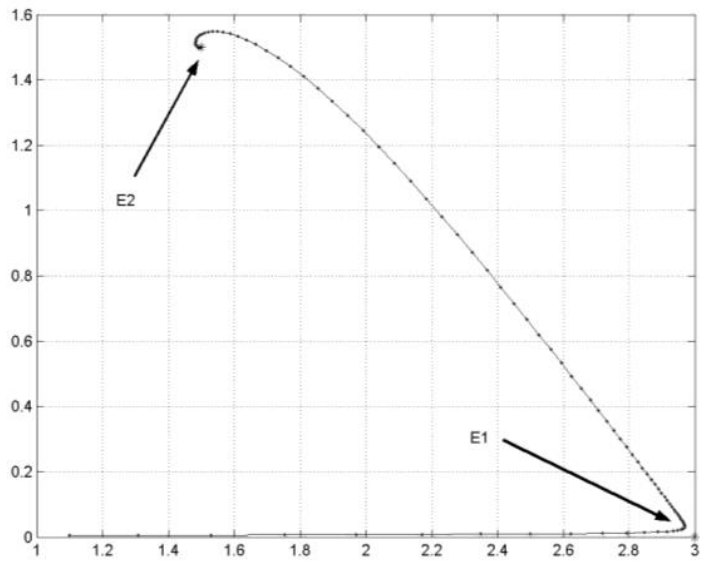

Gambar 1 Plot sistem (7a) dan (7b) dengan $c_{1}=0,1 ; r_{1}=0.3 ; c_{2}=0.1 ; r_{2}=0.2 ; a_{1}=0.1 ; b_{1}=$ $0.1 ; a_{2}=0.1$.

Simulasi numerik berikutnya menggunakan parameter $c_{1}=1 ; r_{1}=3.5 ; c_{2}=0.1 ; r_{2}=0.2 ; a_{1}=$ $0.3 ; b_{1}=0.2 ;$ dan $a_{2}=0.5$. Pada simulasi tersebut, diperoleh nilai eigen pada titik kesetimbangan $E_{1}$ $=(12.5,0)$ adalah $\left|\lambda_{1}\right|=1,5$ dan $\left|\lambda_{2}\right|=1,1$ yang berarti titik kesetimbangan $E_{1}$ source. Adapun nilai eigen yang diperoleh pada titik kesetimbangan $E_{2}=(9.62,1.92)$ adalah $\left|\lambda_{1}\right|=$ 0,89 dan $\left|\lambda_{2}\right|=0,87$ yang berarti titik kesetimbangan $E_{2}$ stabil.

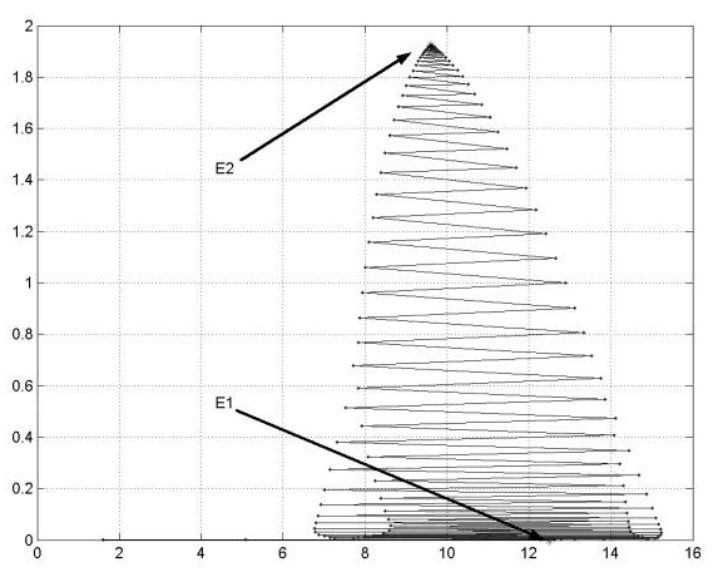

Gambar 2 Plot sistem (7a) dan (7b) dengan $c_{1}=1 ; r_{1}=3.5 ; c_{2}=0.1 ; r_{2}=0.2 ; a_{1}=0.3 ; b_{1}=$ $0.2 ;$ dan $a_{2}=0.5$. 


\section{KESIMPULAN}

Berdasarkan uraian pada hasil dan pembahasan, maka dapat diambil kesimpulan bahwa perilaku model hasil diskritisasi konsisten dengan model kontinunya. Selain itu, pada simulasi numerik dengan Matlab, ditunjukkan bahwa perubahan parameter akan mempengaruhi kestabilan model.

\section{Bibliography}

[1] P. H. Leslie, "Some Furhter Notes on The Use of Matrices in Population Mathematics," Biometrika, vol. 35, pp. 213$245,1948$.

[2] E. P. Aguirre and E. Saez, "Two Limits Cycles in a Leslie-Gower Predator-Prey Model with Additive Allee Effect," Nonlinear Analysis: Real World Applications, vol. 10, no. 3, pp. 1401-1416, 2009.

[3] M. A. Aziz-Alaoui and M. D. Okiye, "Boundedness and Global Stability for a Predator-Prey Model with Modified LeslieGower and Holling-Type II," Applied Math, vol. 16, pp. 1069-1075, 2003.

[4] A. F. Nindjin, M. Aziz-Alaoui and M. Cadivel, "Analysis of a Predator-Prey Model with Modified Leslie-Gower and Holling-type II Schemes with Time Delay," Nonlinear Analysis: Real World Applications, vol. 7, pp. 1104-1118, 2006.

[5] R. Yafia and F. E. Adnani, "Limit Cycle and Numerical Simuations for Small and Large Delays in a Predator-Prey with Modified Leslie-Gower and Holling-type II Schemes," Nonlinear Analysis: Real World Applications, vol. 9, no. 5, pp. 2055-2067, 2008.

[6] L. Chen and L. Chen, "Permanence of a Discrete Periodic Volterra Model with
Mutual Interference," Discrete Dynamics in Nature and Society, 2009.

[7] X. Song and Y. Li, "Dynamic Behaviors of The Periodic Predator-Prey Model with Modified Leslie-Gower Holling-type II Schemes and Impulsive Effect," Nonlinear Analysis: Real World Applications, vol. 9, no. 1, pp. 64-79, 2008.

[8] Y. Zhu and K. Wang, "Existence and Global Attractivity of Positive Periodic Solutions for a Predator-Prey Model with Modified Leslie-Gower Holling-type II Schemes," Journal of Mathematical Analysis and Applications, vol. 384, no. 2, pp. 400-408, 2011.

[9] H. F. Huo, X. Wang and C. C. Chavez, "Dynamics of a Stage-Structured LeslieGower Predator-Prey odel," The Mathematical and Theoretical Biology Institute, 2011. 